Dokuz Eylül Üniversitesi-Mühendislik Fakültesi

Fen ve Mühendislik Dergisi

Cilt 20, Sayı 58, Ocak, 2018
Dokuz Eylul University-Faculty of Engineering Journal of Science and Engineering Volume 20, Issue 58, January, 2018

DOI: $10.21205 /$ deufmd. 2018205805

\title{
Elektronik Sağlık Kayıtlarının Veri Tabanında T-SQL ile Şifrelenmesi ve Başarım Deneyleri
}

\author{
Gökhan DALKILIÇ ${ }^{* 1}$, Enis KARAARSLAN ${ }^{2}$
}

${ }^{1}$ Dokuz Eylül Üniversitesi, Mühendislik Fakültesi, Bilgisayar Mühendisliği Bölümü, 35390, İzmir (ORCID: 0000-0002-0130-1716)

${ }^{2}$ Muğla Sitkı Koçman Üniversitesi, Mühendislik Fakültesi, Bilgisayar Mühendisliği

Bölümü, 48000, Muğla (ORCID: 0000-0002-3595-8783)

(Alınış / Received: 14.01.2017, Kabul / Accepted: 19.10.2017, Online Yayınlanma / Published Online: 20.01.2018)

Anahtar Kelimeler Özet: Sağlık kayıtlarının bilgisayar ortamında tutulması ve güncel Elektronik sağlık hasta verilerine ulaşılabilmesiyle tıbbi süreçlerin etkinliği kayıtları, Veri tabanı şifreleme, T-SQL artmaktadır. $\mathrm{Bu}$ aynı zamanda güvenlik ve mahremiyet sorunlarını da beraberinde getirmektedir. Bu süreçlerde verilerin şifrelenmesi ve şifrelemenin sistemin çalışmasını aksatmadan gerçekleştirilmesi büyük önem taşımaktadır. $\mathrm{Bu}$ çalışma kapsamında, CryptDB ve işlemsel yapılandırılmış sorgu dili (TSQL) tabanlı şifreleme sistemleri kıyaslanmıştır. T-SQL tabanlı şifrelemenin avantajları belirtilmiş, güncel veri seti olarak gözetim, epidemiyoloji ve sonuçlar programı (SEER) kanser verisi değişik boyutlara bölünmüș, şifreli ve şifresiz olarak veri tabanına yüklenmiştir. Şifreli ve şifresiz veri üzerinde sorgular çalıștırılmış, bu ișlemler sonucu elde edilen başarım değerleri verilmiștir.

\section{Encrypting Electronic Health Records with T-SQL in Database and Performance Tests}

\begin{tabular}{l}
\hline Keywords \\
Electronic health \\
records, \\
Database \\
encryption, \\
T-SQL
\end{tabular}

\begin{abstract}
The effectiveness of the medical processes is increasing as health records are kept in a computerized environment and the current patient data are being accessible. This has also caused security and privacy issues. Encryption of the data and implementing the encryption process without disrupting the operation of the system is of paramount importance. In this study, CryptDB and Transact sequential query language (T-SQL) based encryption systems are compared. The advantages of the T-SQL based encryption is specified, and surveillance, epidemiology, and end results program (SEER) cancer data is used as an actual dataset which is then divided into different sizes and stored in the database as encrypted and unencrypted. After running queries on the encrypted and unencrypted data, the performance values that are results of these operations are given.
\end{abstract}




\section{Giriş}

Hastane bilgi sistemlerinin etkinliğinin artırılması süreçlerinde elektronik sağlık kayıtlarının bilgisayar ortamında tutulması ile bu verilerin sınıflandırılması ve anlamlandırılması gerçekleșmiștir. Güncel hasta verilerinin farklı kurumlar tarafından ulaşılabilmesi ile zamandan ve maliyetten tasarruf edilebilmektedir.

Hasta verileri işlenmekte ve farklı kurumlar bu verilere erişim sağlamaktadır. Elektronik sağlık kayıtları kurumlar arasında taşınırken şifrelenmekte ama kurumların iç süreçlerinde ve veri tabanında saklanmasında şifreleme teknolojileri genellikle uygulanmamaktadır. Kurumlar, sistemlerinin yavaşlamasından veya bir ürüne bağımlı olmaktan çekinmektedir [1].

Elektronik sağlık kayıtlarında tutulan hasta bilgilerinin bir kısmı, hassas veri dediğimiz kişisel verilerdir. $\mathrm{Bu}$ veriler birçok ülkede, kanunlara ve uluslararası hukuka göre korunması gereken değerlerdir. Bu verilerin güvenliğinin ve mahremiyetinin sağlanması ve elektronik sağlık kayıtlarına kimin, hangi şartlarda ulaşabileceğinin denetiminin yapılması gerekmektedir. $\mathrm{Bu}$ amaçla, erişimin yetkilendirilmiş kişiler tarafından sağlanması ve kayıtlar veri tabanında depolanırken şifreleme teknolojisinin kullanımı ihtiyacı doğmaktadır. Şifreleme sürecinde yapılacak ek hesaplamalar sistemin işlemci gücünü kullanacağından, bir miktar yavaşlama söz konusu olabilecektir [1].

Tsai ve arkadaşları [2], bulut üzerinde şifreli olarak duran elektronik sağllk kayıtlarına akıllı kart tabanlı eliptik eğri şifreleme sistemi ile erişilebilmesini sağlayan bir sistem önermişlerdir. Ancak, önerilen sistemin performans testi sonuçları verilmemiştir. Her ne kadar eliptik eğri şifreleme sistemi standart asimetrik şifreleme sistemlerine göre daha hızlı çalışsa da simetrik şifreleme sistemlerinden daha yavaștır. Bunun nedeni matematiksel işlemlerin daha fazla olmasindan dolayı daha uzun sürede çalışmasındandır.

Fernandez-Aleman ve arkadașlarının yazdıkları inceleme makalesinde [3], inceledikleri çalışmalarda simetrik ve asimetrik şifreleme tekniklerinin eşit miktarda kullanıldığını ancak simetrik şifrelemenin daha hızlı olduğu ve büyük veriler için simetrik şifrelemenin daha verimli olduğu belirtilmiştir. Ayrıca, asimetrik şifrelemenin ise bazı gizlilik zafiyetleri içerdiğine değinilmiștir. Aynı çalışmada, hasta kayıtlarının şifrelenmesi için geliştirilecek bir sistemin yeni kayitların eklenmesini kolaylıkla desteklemesi gerektiği sonucuna varılmıştır.

Mohammed ve arkadaşları yaptıkları çalışmada [4], veri madenciliği için elektronik sağlık kayıtlarını içeren veri tabanlarının güvenli bir şekilde yönetimini sağlamak amacıyla bir yapı (framework) önermişlerdir. Bu yapı, hasta kayıtlarına ulașmak isteyen istemcinin önüne güvenli bir vekil yerleştirip, bu vekil aracıllğıyla şifreli sorguların veri tabanına iletilmesi ve sonuçların şifreli olarak alınmasını içermektedir. Ancak, benzer CryptDB tabanlı diğer bir çalışmada [5] olduğu gibi sadece birtakım SQL sorgusu için destek sunulmuştur.

Bu çalıșmada; ikinci bölümde șifreleme konusundaki temel kavramlar ve veri tabanlarının şifrelenmesinde kullanılan farklı şifreleme yöntemleri tanıtılmış ve bu yöntemler karşılaştırılmıștır. Üçüncü bölümde, uygulamanın yapıldığı ortam, veri seti ve yöntem ele alınmıș, yapılan deney sonuçları tablolar halinde verilerek yorumlanmıştır. Son bölümde, sonuçlar ve gelecek çalışmalar sunulmuştur. 


\section{Temel Kavramlar}

\section{1. Şifreleme Yöntemi Algoritmanın Seçilmesi}

Şifreleme süreçlerinde, çeşitli şifreleme algoritmalarından amaca en uygun şifreleme algoritmasının seçilmesi önem arz etmektedir. Algoritma seçiminde aşağıdaki kriterlerden söz edilebilir:

- Güçlü Şifreleme: Şifreleme algoritmasına yapılacak saldırılara karşı algoritmanın dayanıklılığı güçlü şifrelemeyi tanımlar. Bazı algoritmaların ne kadar güçlü oldukları matematiksel yöntemler veya saldırı deneyleri ile ortaya konulmuştur $[6,7]$.

- Anahtar uzunluğu: Anahtar uzunluğu şifrelemenin başarımını etkilemektedir. Bazı algoritmalarda, farklı anahtar uzunluğunun seçilebilmesi mümkündür ve daha uzun anahtarlar daha güçlü şifreleme anlamına gelmektedir. Uzun anahtar seçilmesinin dezavantajı ise anahtarın üretiminde ve dağıtımındaki zorluktur.

- İşlemci gücü: Şifreleme ve deşifrelemede merkezi işlem biriminin ne oranda kullanıldığını tanımlar. Güçlü șifreleme algoritmaları ve uzun anahtarlar, daha fazla ișlemci kaynağı harcamaktadır [8].

Simetrik șifreleme algoritmaları; asimetrik şifreleme algoritmalarına göre daha performanslı çalıșacaklarından, özellikle yüksek miktarda veri şifreleneceği zaman tercih edilmesi önerilmektedir. Anahtar dağıtımı gibi düşük miktardaki verilerde asimetrik şifreleme süreçleri etkin olarak kullanılmaktadır. Verinin daha az yer kaplaması için sıkıştırma algoritmaları kullanılabilir. Burada dikkat edilmesi gereken unsur, şifrelenmiş veri sıkıştırılamayacağı için verinin şifrelenmeden önce sıkıştırılmasıdır [8]. Ayrıca, veri tabanındaki bütün alanlar yerine bir kısmının şifrelenmesi (kısmi şifreleme) ya da verilerin anonimleștirilmesi de şifreleme sürecinin performansını olumlu yönde etkilemektedir.

\subsection{CryptDB}

CryptDB [5] Massachusetts Institute of Technology (MIT)'de geliștirilmekte olan, uygulama ve veri tabanı arasında vekil (proxy) olarak çalışan ve veri tabanını şifreleyerek güvenliğini sağlayan bir sistemdir. Vekil tabanlı çalışan veri tabanı şifreleme sistemlerinin çoğu, CryptDB'nin tasarımına dayanmaktadır. $\mathrm{Bu}$ sistemler, rastgele olmayan şifreleme (deterministic encryption DTE) ve sira koruyarak şifreleme (order preserving encryption OPE) gibi örnekleri olan özellik koruyarak şifreleme (property preserving encryption PPE) şemalarını kullanmaktadır [9].

CryptDB ve benzeri geliștirilmekte olan sistemlerin en büyük sıkıntıları; dokümantasyon eksikliği ve her yazılım geliştirme ortamı için destek ve kütüphanelerinin olmamasıdır. CryptDB'nin kısıtlamaları Patel ve Jiang'ın çalıșmasında [10] incelenmiștir. CryptDB gibi sistemlerin en büyük dezavantajı, SQL'in sadece bir kısmını destekleyebilmeleridir. Örneğin "in", "not", "update" işlemleri desteklenmekte ama "like" cümlesi desteklenmemektedir [11].

Güncel bir tez çalışmasında [12] yapılan testlerde, veri tabanındaki veriler arttıkça sistemin çok ciddi șekilde yavaşladığı; CryptDB'nin var olan sürümünün muhtemelen bellek yönetiminde ve iş parçacı̆̆ işlemede (thread handling) güvenilir olmadığ sonucuna varılmıştır. CryptDB; güvenilir bir bulut tabanlı uygulama sunucusu ve vekili ile çalıştığını varsaydığından, daha zayıf bir saldırgan modeli sunmaktadır [13]. CryptDB'nin mimarisinden dolayı yapılabilecek saldırılar Naveed ve 
arkadaşlarının çalışması [9] ve Akın ve Sunar'ın çalışmasında [14] incelenmiştir. Elektronik sağlık verilerinin veri tabanına CryptDB ile şifrelenmiş olarak yüklendiği Naveed ve arkadaşlarının çalışmasında [9], sorguların çalışması için şifreleme katmanının yeterince soyulması (peel) durumunda çok miktarda hassas verinin ele geçirilebileceği gösterilmiştir. Belirtilen çalışmada, frekans analizi ve sıralaması (frequency analysis and sorting), kombinatoryal optimizasyon gibi saldırılar kullanılmıștır. Saldırılarda sadece şifrelenmiş sütunlar ve genel kullanıma açık dış verilerden yararlanılmıştır. Hasta kayıtlarının OPE ile şifrelenmiş belirli niteliklerinin \%80'inden, DTE ile şifrelenmiş belirli niteliklerinin \%60'ından fazlasının ele geçirilebileceği gösterilmiştir.

\subsection{Transact SQL (T-SQL)}

İşlemsel yapılandırılmış sorgu dili (Transact sequential query language $\mathrm{T}$ SQL) şifreleme özelliği Microsoft SQL Server 2005 'den itibaren gelen bir eklentidir. SQL Server, Windows CryptoAPI (CAPI)'yi kullanan bütünleşik bir şifreleme güvenlik modeli sunmaktadır. Anahtar yönetimi ise ANSI X9.17'deki metoda benzer katmanlı bir yapıdadır [15].

Microsoft CAPI [16], farklı Microsoft Windows işletim sistemleri bünyesinde bulunan bir uygulama programlama ara yüzüdür. Gelişmiş şifreleme standardı (Advanced encryption standard AES), üç kat veri şifreleme standardı (Triple data encryption standard DES), Rivest şifreleme 5 (Rivest cipher 5 RC5) ve güvenli özet çlkarma algoritması (Secure hashing algorithm 1 SHA-1) gibi çok sayıda şifreleme ve özet çıkarma algoritmasını destekler. MsSQL Server, Microsoft CAPI'yi kullanan şifreleme, şifre çözme, sayısal imza ve doğrulama üzerine birçok fonksiyon ve özelliğe sahiptir. Bu fonksiyonlar ise simetrik ve asimetrik şifreleme ve şifre çözme, sayısal imza ve imza doğrulama, otomatik anahtar taşıma ile simetrik şifreleme, özet (hash) ile şifreleme ve sertifika kopyalama fonksiyonlarıdır.

Microsoft SQL Server'da veri tabanı seviyesinde şifreleme iki farklı şekilde yapılabilir:

- Şeffaf veri şifreleme (transparent data encryption), veri tabanı motoru tarafindan otomatik olarak gerçekleştirilen ve veri tabanının bütününe uygulanan bir şifreleme yöntemidir. Veri tabanı şifrelemede kullanılan anahtar sertifika tarafindan korunur ve bu sertifika olmadan veri tabanı dosyası başka bir SQL sunucusunda çalışmaz. Veri tabanı şifreleme işlemi sayfa seviyesinde yapılır, diskte bulunan veri tabanı dosyaları şifreli olarak saklanır. Veriler ara bellekte şifrelenmemiş olarak kalır. Veri tabanı ile ilişskilendirilmiş uygulamanın modifiye edilmesine ihtiyaç duyulmaz [8].

- Sütun seviyesinde şifrelemede (column-level encryption) şifreleme işlemi kolon bazlı olarak sadece istenen kolonun şifrelenmesi şeklinde gerçekleştirilir. Veriler şifrelenmiş olarak belleğe yüklenir ve şifreleme/deșifreleme fonksiyonları (EncryptByKey, DecryptByKey) çalıştırılmadan işlenmez. Performans şifrelenecek sütun ve satır adedine göre değişir ve bu şifreleme yöntemi indekslemeyi desteklemez. Karmaşık bir ișlem olmasına karșın șeffaf veri şifreleme ve sütun seviyesinde șifreleme birlikte kullanılabilir [8].

\subsection{CryptDB ve T-SQL'in Karşılaştırılması}

CryptDB ve T-SQL'in temel özelliklerinin karşılaştırılması Tablo 1'de verilmiştir. Tabloda da belirtildiği üzere CryptDB sadece tablonun tümü üzerinden şifrelemeye imkân tanırken, T-SQL ile 
tablonun tümü ya da sütun bazlı bir şifrelemeyi değil, hem simetrik hem de kısmı şifrelenebilir. Ayrıca, T-SQL'in en asimetrik şifrelemeyi farklı algoritma büyük avantaj sağladı̆̆ı kısım tüm SQL destekleri ile sağlamaktadır. T-SQL'in sorgularının çalıştırılabilmesidir, ancak belirtilen avantajlarından dolayı sağlık CryptDB kullanımında SQL sorgularının kayıtlarının şifrelenmesi amacıyla bir kısmı desteklenmektedir. T-SQL, çalışmamızda T-SQL kullanılmıştır. CryptDB'de olduğu gibi sadece simetrik

Tablo 1. CryptDB ve T-SQL karşılaștırılması

\begin{tabular}{|c|c|c|}
\hline & CryptDB & T-SQL \\
\hline Anahtar yönetimi & $\begin{array}{c}\text { Sistemdeki kullanıcı } \\
\text { parolalarını anahtarlara } \\
\text { bağlama }\end{array}$ & $\begin{array}{l}\text { ANSI X9.17'deki metoda benzer } \\
\text { katmanlı bir anahtar dağıtım yönetimi }\end{array}$ \\
\hline Şifrelenen veri & Bütün veri tabanı & Tüm veya kısmi (sütun bazında) veriler \\
\hline $\begin{array}{l}\text { Şifreleme } \\
\text { yöntemleri }\end{array}$ & $\begin{array}{c}\text { Simetrik şifreleme tabanlı } \\
\text { katmanlı şifreleme (onions of } \\
\text { encryption) ve bazı süreçlerde } \\
\text { homomorfik șifreleme }\end{array}$ & $\begin{array}{l}\text { Simetrik ve asimetrik şifreleme, özet } \\
\text { (hash) fonksiyonları }\end{array}$ \\
\hline $\begin{array}{l}\text { Şifreleme } \\
\text { algoritmaları }\end{array}$ & $\begin{array}{l}\text { Her katman (onion) için farklı; } \\
\text { 128-bit AES, Blowfish, Paillier } \\
\text { kripto sistemi, Song şifreli veri } \\
\text { arama algoritması }\end{array}$ & $\begin{array}{c}\text { Desteklenen simetrik şifreleme } \\
\text { algoritmaları: DES, Triple DES, } \\
\text { Triple_DES_3KEY, RC2, RC4, 128-bit } \\
\text { RC4, DESX, 128-bit AES, 192-bit AES, } \\
\text { 256-bit AES }\end{array}$ \\
\hline SQL desteği & SQL'in sadece bir kısmı & Tam destek \\
\hline Çalışma ortamı & $\begin{array}{l}\text { Linux (Ubuntu'nun belirli bir } \\
\text { sürümü üzerine sorunsuz } \\
\text { kurulmaktadır) }\end{array}$ & $\begin{array}{l}\text { Microsoft SQL Server } 2012 \text { ve sonrası; } \\
\text { bulut ortamında Azure SQL veri tabanı } \\
\text { ve SQL Data Warehouse }\end{array}$ \\
\hline $\begin{array}{l}\text { Çalıșma ortamı } \\
\text { (Sunucu, bulut } \\
\text { altyapısı) }\end{array}$ & $\begin{array}{c}\text { Bulut ortamı hedeflenmiş bir } \\
\text { veri tabanı yönetim sistemidir, } \\
\text { tek bir sunucu üzerinde de } \\
\text { çalıșabilir [13] }\end{array}$ & $\begin{array}{c}\text { Bulut ortamında çalışabileceği gibi diğer } \\
\text { platformlarda da çalışabilir }\end{array}$ \\
\hline $\begin{array}{l}\text { Uygulama ve veri } \\
\text { tabanında } \\
\text { değişiklik }\end{array}$ & $\begin{array}{l}\text { Uygulamada ve veri tabanında } \\
\text { ufak değişiklikler sonrası } \\
\text { şeffaf olarak çalıșacağı } \\
\text { belirtilmekle birlikte sorunlar } \\
\text { yaşanabilmektedir [12] }\end{array}$ & $\begin{array}{l}\text { Uygulamada T-SQL'e ait fonksiyonlar } \\
\text { kullanılır }\end{array}$ \\
\hline
\end{tabular}

\section{Uygulama}

Şifreli ve şifresiz veri üzerinde yapılan çözümlemeler, yerel bir bilgisayar üzerinde gerçekleşmiştir. Yerel bilgisayar üzerinde Windows 10 Professional işletim sistemi çalışmakta olup Intel Core 2 Duo işlemci ve 4 GB bellek bulunmaktadır. Microsoft SQL Server Express ve Standart sürümü şeffaf veri şifrelemeyi desteklemediğinden, Microsoft SQL Server Enterprise (64-bit) 12.0.4213.0 sürümü kullanılmıştır.

\subsection{Veri Seti}

$\mathrm{Bu}$ çalışmada, verilerin şifreli saklanmasının ve işlenmesinin sorgulama performansı üzerindeki etkilerini gözlemlemek amacıyla test verisi olarak gözetim, epidemiyoloji ve sonuçlar programı (surveillance, epidemiology, and end results program SEER) kanser verileri kullanılmıştır [17]. 1973 ile 2012 yılları arasinda gerçekleşen toplam 4.524.099 kanser vakasını içeren anonim bir veri setidir. İçeriğinde hastaya ait numara, etnik köken, doğum tarihi ve yeri, teşhisin konulduğu ay, yıl ve bu esnadaki 
G. Dalkılıç, E. Karaarslan / Elektronik Sağlık Kayıtlarının Veri Tabanında T-SQL ile Şifrelenmesi ve Başarım Deneyleri

hastanın yaşı ve medeni durumu, hastalığın seyri ile ilgili tümörün büyüklüğü ve yeri, tekrar etme sayısı, ameliyat durumu, hastanın hayatta olup olmadığı gibi bilgilerden oluşan toplam 150 alan bulunmaktadır. Kanser türlerine göre ayrılmış 9 farklı dosyada metin formatında paylaşılan bu veri, çalışmamız sürecinde geliştirilen bir uygulama aracılığıyla MSSQL üzerinde hazırlanan veri tabanına aktarılmıştır.

\subsection{Yöntem}

CryptDB ve T-SQL yöntemlerinin kıyaslanması sonucunda, aşağıdaki nedenlerden dolayı T-SQL yönteminin kullanılmasına karar verilmiştir:

- CryptDB'nin çözülmesi gereken bazı sorunları olduğu ve bir ürün olarak kullanılmaya hazır olmaması [12],

- T-SQL'in kısmi (sütun bazında) şifreleme yapabilmesi,

- T-SQL'in farklı şifreleme algoritmalarının seçimini mümkün kılması,

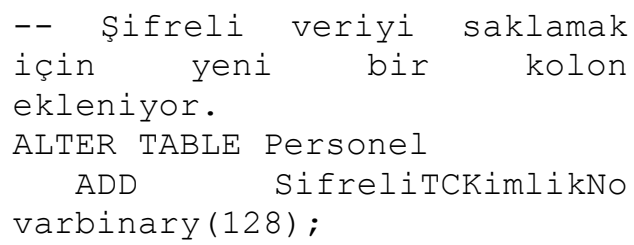

Yukarıdaki sorguda kullanılan TCNo_Key_01 isimli simetrik anahtarın - T-SQL'in SQL'i tam olarak oluşturulması için CREATE SYMMETRIC desteklemesidir. $\quad$ KEY fonksiyonu şu şekilde kullanılmıştır:

Bu çalışmada, sütun seviyesinde şifrelemede simetrik şifreleme kullanılmış ve T-SQL şifreleme fonksiyonlarından ENCRYPTBYKEY yöntemi tercih edilmiştir. Ayrıca, şeffaf veri şifreleme yöntemi de test edilmiştir. Bir veri tabanı sütununun ENCRYPTBYKEY fonksiyonu ile AES algoritması kullanılarak şifrelenmesine dair bir örnek aşağıda verilmiştir. Örnekte, personel tablosunun TCKimlikNo kolonunda bulunan veriler şifrelenerek yeni oluşturulan SifreliTCKimlikNo sütununda saklanmıştır.

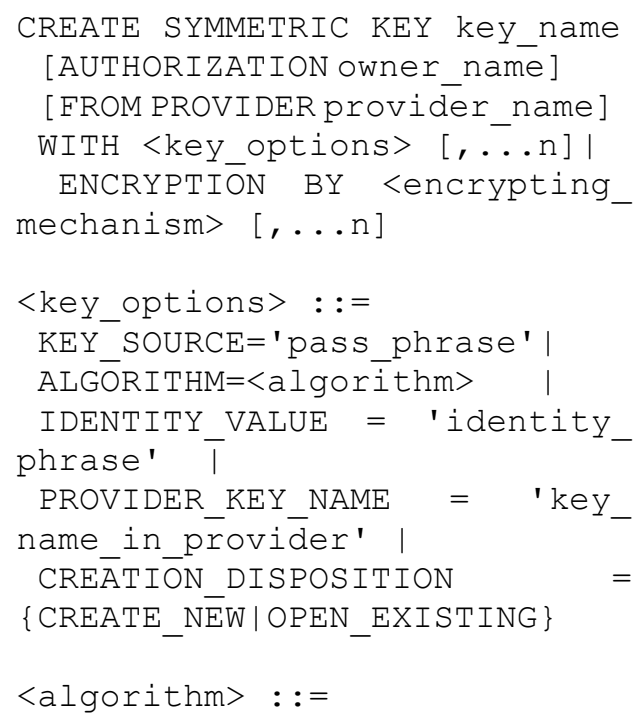


G. Dalkılıç, E. Karaarslan / Elektronik Sağlık Kayıtlarının Veri Tabanında T-SQL ile Şifrelenmesi ve Başarım Deneyleri

DES | TRIPLE_DES | TRIPLE_DES

3KEY $|\mathrm{RC} 2| \mathrm{RC} \overline{4}|\mathrm{RC} 4128| \mathrm{DE} \mathrm{SX} \mid$

AES_128|AES_192| $\bar{A} E S \_256$

<encrypting_mechanism> : :=

CERTIFICATE certificate_name

| PASSWORD='passWord' |

SYMMETRIC KEY symmetric_

key_name |

ASYMMETRIC KEY asym_key_name

Kullanılan AES algoritması 16 baytlık veriyi girdi olarak kabul edip, 16 baytlık şifreli veri üretmektedir. Ancak, AES bir blok şifreleme metodu olduğu için 16 bayttan az veri girdi olarak verildiğinde veriyi 16 bayta uzatır (padding). Şifrelenmiş veride bulunan ek alanların nelerden oluştuğu Natarajan ve arkadaşları [18] tarafından verilmiştir. Örneğin; "1" değerinin veri tabanında tutulan şifrelenmiş hali şu şekildedir:

0027BFE329DD0E479A728B09A0408 0E201000000A70C10882D17F71CDA D7A 76D823F318E67FABB36DAEC 657 2C51EEF18CF1DC607
Örnek şifrelenmiş veride bulunan alanlar ve büyüklükleri Tablo 2'de verilmiștir. Tablo 2'den de görüldüğü üzere en iyi ihtimalle 16 bayt uzunluğunda girilmiş olan düz metin, 52 bayt uzunluğunda şifreli metine dönüşmektedir. $\mathrm{Bu}$ durumda veri \%225 oranında artmaktadır. En kötü durum senaryosunda ise, yani girilen içeriğin 1 bayt olması durumunda ise \%5100 şeklinde çok yüksek bir oranda artmaktadır.

Farklı veri büyüklüklerinin, şifreli veri üzerinden sorgulama yapmayı nasıl etkilediğini anlamak için veri seti bölünerek 50.000 - 500.000 arası 50șer bin artırlarak 10 farklı veri seti oluşturulmuştur. Bu veri setleri, şifreli ve şifresiz olarak bilgisayarda kurulan SQL veri tabanında saklanmıştır. Şifreleme veri tabanı katmanında gerçekleştirilmiş, şeffaf veri şifreleme ve sütun seviyesinde şifreleme yöntemleri uygulanmıştır.

Tablo 2. AES ile șifrelenmiș veride bulunan alanlar [18]

\begin{tabular}{|c|c|c|}
\hline Açıklama & $\begin{array}{c}\text { Büyüklük } \\
\text { (bayt) }\end{array}$ & Örnek İçerik \\
\hline $\begin{array}{c}\text { Simetrik șifrenin evrensel } \\
\text { tekil belirteci (Globally unique } \\
\text { identifier - GUID) }\end{array}$ & 16 & 0027BFE32 9DD0E4779A72 8B09AA0 40 80E2 \\
\hline Sürüm numarası & 4 & 01000000 \\
\hline $\begin{array}{c}\text { Rastgele üretilen ilk vektör } \\
\text { (initial vector IV) }\end{array}$ & 16 & A70C10882D17F71CDAD7A76D823F318E \\
\hline AES ile şifrelenmiş veri & 16 & 67FABB36DAEC6572C51EEF18CF1DC607 \\
\hline Toplam & 52 & \\
\hline
\end{tabular}

Şifreli ve şifresiz veri tablolarının oluşturulma süreleri ve boyutları Tablo 3'de belirtilmiştir. Tablo 3'den de görüldüğü üzere, verinin sütun seviyesinde şifreleme yöntemi ile şifreli saklanmasıyla tüm kayıt sayılarında tablo boyutu yaklaşık 11 kat artmıştır. Şeffaf şifreleme yönteminde tablo boyutunda herhangi bir değişiklik olmadığı için Tablo 3'de ayrı bir kolon olarak belirtilmemiștir. Tablo 3'de görülen şifreli ve şifresiz tablo boyutları arasındaki farkın nedeni, Tablo 2'de gösterildiği gibi 16 baytllk bir verinin sistem tarafından 52 bayta arttırılması ve ayrıca 16 bayttan küçük her türlü girdinin 16 bayta tamamlanarak şifrelenmesidir. Şifresiz veriler için tablo olușturma süreleri ile şifreli verilerin tablolarının oluşturulma süreleri karşılaştırıldığında, veri boyutunun büyümesinden dolayı süreler arasında 
büyük farklar oluştuğu Tablo 3 'de oluşturulurken bu işlemin 1 defa görülmektedir. Ancak, bu süreler yapılacağı düşünüldüğünde sürelerin tabloların ilk defa oluşturulma süreleri gözardı edilebilir süreler olduğu olduğundan ve veri tabanı görülmektedir.

Tablo 3. Farklı büyüklükteki şifreli ve şifresiz veri tablolarının oluşturulma süreleri (sn) ve boyutları (MB)

\begin{tabular}{|r|r|r|r|r|}
\hline Kayıt Sayısı & $\begin{array}{c}\text { Şifresiz tablo kaylt } \\
\text { süresi (dakika saniye } \\
\text { milisaniye) }\end{array}$ & $\begin{array}{c}\text { Şifreli tablo } \\
\text { kayıt süresi }\end{array}$ & $\begin{array}{c}\text { Şifresiz tablo } \\
\text { boyutu (MB) }\end{array}$ & $\begin{array}{r}\text { Şifreli tablo } \\
\text { boyutu (MB) }\end{array}$ \\
\hline 50.000 & 9s 369ms & $2 \mathrm{~d} 34 \mathrm{~s}$ & 35,602 & 429,695 \\
\hline 100.000 & $16 \mathrm{~s} 600 \mathrm{~ms}$ & $5 \mathrm{~d} 14 \mathrm{~s}$ & 71,148 & 859,383 \\
\hline 150.000 & $25 \mathrm{~s} 693 \mathrm{~ms}$ & $8 \mathrm{~d} 36 \mathrm{~s}$ & 106,695 & $1.289,070$ \\
\hline 200.000 & $45 \mathrm{~s} 879 \mathrm{~ms}$ & $10 \mathrm{~d} 25 \mathrm{~s}$ & 142,242 & $1.718,758$ \\
\hline 250.000 & $1 \mathrm{~d} 2 \mathrm{~s} 919 \mathrm{~ms}$ & $12 \mathrm{~d} 47 \mathrm{~s}$ & 177,789 & $2.148,445$ \\
\hline 300.000 & $1 \mathrm{~d} 17 \mathrm{~s} 698 \mathrm{~ms}$ & $15 \mathrm{~d} 34 \mathrm{~s}$ & 213,336 & $2.578,133$ \\
\hline 350.000 & $1 \mathrm{~d} 29 \mathrm{~s} 859 \mathrm{~ms}$ & $17 \mathrm{~d} 47 \mathrm{~s}$ & 248,883 & $3.007,820$ \\
\hline 400.000 & $1 \mathrm{~d} 38 \mathrm{~s} 690 \mathrm{~ms}$ & $20 \mathrm{~d} 23 \mathrm{~s}$ & 284,430 & $3.437,508$ \\
\hline 450.000 & $1 \mathrm{~d} 50 \mathrm{~s} 898 \mathrm{~ms}$ & $22 \mathrm{~d} 56 \mathrm{~s}$ & 319,977 & $3.867,195$ \\
\hline 500.000 & $2 \mathrm{~d} 7 \mathrm{~s} 819 \mathrm{~ms}$ & $25 \mathrm{~d} 06 \mathrm{~s}$ & 355,523 & $4.296,891$ \\
\hline
\end{tabular}

50.000 - 500.000 arası tüm kayıtlar üzerinde çalıştırılan sorguların şifresiz ve şifreli veri tabanları üzerinde çalıștırılacak sürümleri Tablo 4'de detaylı bir șekilde verilmiștir. Verilen ilk 3 sorgu, "where" anahtar kelimesi ile çalışan sorgulardır. Sorgulardan ilki, sabit bir tanımlayıcıya sahip hastayı arama işlemi, ikincisi doğum yeri Türkiye olan hastaların kayıtlarını sayma işlemi, üçüncüsü ise yaşı 20 ile 30 arasında olan hastaların kayıtlarını sayma işlemidir. 4. sorgu ise bir siralama operatörü sorgusudur ve hastaları doğum tarihlerine göre azalan sirayla sıralayarak, hasta tanımlayıcılarını ve buna karşılık gelen doğum tarihlerini listelemektedir. 5. sorgu bir gruplama operatörü sorgusudur, bu sorgu kanser tümörünün görüldüğü alana göre gruplama yapar. 6. sorgu küme operatörü örneğidir ve görünen farklı boyuttaki tümör büyüklükleri listelemek amacıyla kullanılmıştır. 7. ve 8. sorgular biriktirme (aggregate) operatörü örnekleridir. 7. sorgu teşhisin konulduğu anda hastaların ortalama yaşını hesaplamaktadır. 8. sorgu teşhisin konulmasindan sonra hastanın maksimum kaç ay daha hayatta kaldığının sonucunu döndürmektedir.

Tablo 4'de verilen her bir sorgu 50.000500.000 arası tüm kayıtlar için çalıştırılmış ve her bir sorgunun şifresiz, şeffaf şifreli ve şifreli veriler üzerinde çalışma süreleri Tablo 5'de verilmiștir. İşletim sisteminden kaynaklanan işlemlerden dolayı sürelerin daha sağlıklı hesaplanabilmesi için her bir sorgu 100 defa çalıştırılmış ve ortalama değer hesaplanmıștır. Şifresiz ve şeffaf şifreli tablolar üzerinde uygulanan sorguların çoğunun çalışma süresi milisaniye seviyesinde iken, şifreli tablolarda süreler saniyeler hatta dakikalar seviyesine çlkmaktadır. Bunun ilk nedeni, şifreli tabloların boyutlarının Tablo 3'de verildiği gibi şifresiz tablo boyutlarından büyük olmasıdır. İkinci nedeni ise şifreli tablolarda yapılan sorgu işlemlerinde tablodaki verinin şifresinin çözülmesinin ardından sorgunun çalışmasıdır. Şeffaf şifreli ve şifresiz tabloların yer aldığı veri tabanı dosyaları aynı uzunlukta olduğundan her iki yöntemde de uygulanan sorguların süreleri hemen hemen aynıdır. 
G. Dalkılıç, E. Karaarslan / Elektronik Sağlık Kayıtlarının Veri Tabanında T-SQL ile Şifrelenmesi ve Başarım Deneyleri

Tablo 4. Performans testlerinde kullanılan örnek sorgular

\begin{tabular}{|c|c|c|c|c|}
\hline \multicolumn{2}{|c|}{ Operatör } & No & Şifresiz Sorgu & Şifreli Sorgu \\
\hline \multirow{3}{*}{ 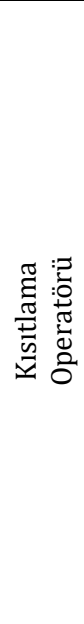 } & $\begin{array}{c}\text { Where } \\
><=\end{array}$ & 1 & $\begin{array}{r}\text { SELECT * FROM } \\
\text { INCIDENCE WHERE } \\
\text { Patient_ID_number = } \\
\text { '07000155' }\end{array}$ & $\begin{array}{r}\text { SELECT } \\
\text { CONVERT(NCHAR(8),DECRYPTBYKEY(Patient_ } \\
\text { ID_number)), CONVERT(varchar(3), } \\
\text { DECRYPTBYKEY(Age_at_diagnosis)) FROM } \\
\text { INCIDENCE WHERE } \\
\text { CONVERT(NCHAR(8),DECRYPTBYKEY(Patient_ } \\
\text { ID_number)) = '07000155' }\end{array}$ \\
\hline & $\begin{array}{l}\text { Where } \\
\text { LIKE }\end{array}$ & 2 & $\begin{array}{r}\left.\text { SELECT COUNT( }{ }^{*}\right) \\
\text { FROM INCIDENCE } \\
\text { WHERE } \\
\text { Birthplace_country } \\
\text { LIKE 'TUR' }\end{array}$ & $\begin{array}{r}\text { SELECT COUNT }\left(^{*}\right) \text { as Count FROM INCIDENCE } \\
\text { WHERE } \\
\text { CONVERT(NCHAR(3),DECRYPTBYKEY(Birthpl } \\
\text { ace_country)) LIKE 'TUR' }\end{array}$ \\
\hline & \begin{tabular}{|c|} 
Where \\
BETWEEN
\end{tabular} & 3 & $\begin{array}{r}\text { SELECT COUNT(*) } \\
\text { FROM INCIDENCE } \\
\text { WHERE } \\
\text { Age_at_diagnosis } \\
\text { BETWEEN 20 AND } 30\end{array}$ & $\begin{array}{r}\text { SELECT COUNT }{ }^{*} \text { ) as Count FROM INCIDENCE } \\
\text { WHERE } \\
\text { CONVERT(varchar(3),DECRYPTBYKEY(Age_at_ } \\
\text { diagnosis)) BETWEEN } 20 \text { AND } 30\end{array}$ \\
\hline 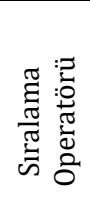 & OrderBy & 4 & $\begin{array}{r}\text { SELECT } \\
\text { Patient_ID_number, } \\
\text { Year_of_Birth FROM } \\
\text { INCIDENCE } \\
\text { ORDER BY } \\
\text { Year_of_Birth desc }\end{array}$ & $\begin{array}{r}\text { SELECT } \\
\text { CONVERT(NCHAR(8),DECRYPTBYKEY(Patient_- } \\
\text { ID_number)), } \\
\text { CONVERT(varchar(4),DECRYPTBYKEY(Year_of } \\
\text { _Birth)) AS Year_of_Birth FROM INCIDENCE } \\
\text { ORDER BY Year_of_Birth desc }\end{array}$ \\
\hline 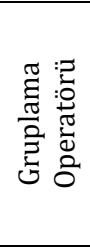 & GroupBy & 5 & $\begin{array}{r}\text { SELECT Primary_Site, } \\
\left.\text { COUNT }{ }^{*}\right) \text { FROM } \\
\text { INCIDENCE } \\
\text { GROUP BY } \\
\text { Primary_Site }\end{array}$ & $\begin{array}{r}\text { SELECT } \\
\text { CONVERT(NCHAR(4),DECRYPTBYKEY(Primar } \\
\text { y_Site)) AS Primary_Site, COUNT(*) as Count } \\
\text { FROM INCIDENCE } \\
\text { GROUP BY } \\
\text { CONVERT(NCHAR(4),DECRYPTBYKEY(Primar } \\
\text { y_Site)) }\end{array}$ \\
\hline 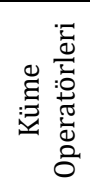 & Distinct & 6 & $\begin{array}{l}\text { SELECT DISTINCT } \\
\text { EOD_Tumor_Size } \\
\text { FROM INCIDENCE }\end{array}$ & $\begin{array}{r}\text { SELECT DISTINCT } \\
\text { CONVERT(NCHAR(3),DECRYPTBYKEY(EOD_Tu } \\
\text { mor_Size)) FROM INCIDENCE }\end{array}$ \\
\hline 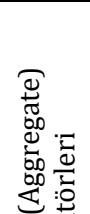 & $\begin{array}{c}\text { Sum, } \\
\text { Average }\end{array}$ & 7 & $\begin{array}{r}\text { SELECT } \\
\text { AVG(Age_at_diagnosis) } \\
\text { FROM INCIDENCE } \\
\text { WHERE } \\
\text { Age_at_diagnosis!= } \\
\text { '999' }\end{array}$ & $\begin{array}{r}\text { SELECT AVG(CONVERT(int, } \\
\text { CONVERT(varchar(3),DECRYPTBYKEY(Age_at_ } \\
\text { diagnosis)))) FROM INCIDENCE WHERE } \\
\text { CONVERT(varchar(3),DECRYPTBYKEY(Age_at_- } \\
\text { diagnosis)) != '999' }\end{array}$ \\
\hline 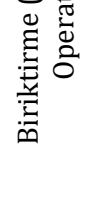 & Min, Max & 8 & $\begin{array}{r}\text { SELECT } \\
\text { MAX(Survival_months) } \\
\text { FROM INCIDENCE } \\
\text { WHERE } \\
\text { Survival_months <> } \\
\text { '9999' }\end{array}$ & $\begin{array}{r}\text { SELECT MAX(CONVERT(int, } \\
\text { CONVERT(NCHAR(4),DECRYPTBYKEY(Surviva } \\
\text { l_months)))) FROM INCIDENCE WHERE } \\
\text { CONVERT(NCHAR(4),DECRYPTBYKEY(Surviva } \\
\text { l_months)) <> '9999' }\end{array}$ \\
\hline
\end{tabular}


G. Dalkılıç, E. Karaarslan / Elektronik Sağlık Kayıtlarının Veri Tabanında T-SQL ile Şifrelenmesi ve Başarım Deneyleri

Tablo 5. Şifreli, şeffaf şifreli ve şifresiz farklı boyuttaki tablolar üzerinde örnek sorguların çalışma süreleri

\begin{tabular}{|c|c|c|c|c|c|c|c|c|c|}
\hline \multirow{2}{*}{\multicolumn{2}{|c|}{ Tablolar }} & \multicolumn{8}{|c|}{ SORGULAR (ms) } \\
\hline & & 1 & 2 & 3 & 4 & 5 & 6 & 7 & 8 \\
\hline \multirow{10}{*}{ 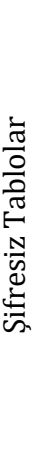 } & 50.000 & 18 & 24 & 14 & 317 & 31 & 26 & 19 & 25 \\
\hline & 100.000 & 27 & 32 & 15 & 452 & 31 & 29 & 19 & 26 \\
\hline & 150.000 & 33 & 37 & 18 & 640 & 47 & 41 & 30 & 40 \\
\hline & 200.000 & 42 & 56 & 26 & 972 & 62 & 55 & 40 & 51 \\
\hline & 250.000 & 53 & 64 & 34 & 196 & 82 & 73 & 49 & 66 \\
\hline & 300.000 & 64 & 69 & 38 & 1s 475 & 93 & 90 & 57 & 78 \\
\hline & 350.000 & 74 & 81 & 44 & 1s 746 & 108 & 96 & 67 & 90 \\
\hline & 400.000 & 84 & 94 & 55 & 2s 16 & 122 & 109 & 78 & 102 \\
\hline & 450.000 & 95 & 106 & 61 & 2s 263 & 139 & 122 & 93 & 118 \\
\hline & 500.000 & 110 & 117 & 62 & 2s 543 & 152 & 137 & 103 & 128 \\
\hline \multirow{9}{*}{ 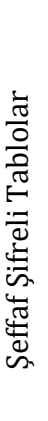 } & 50.000 & 21 & 26 & 14 & 359 & 35 & 31 & 22 & 28 \\
\hline & 100.000 & 32 & 34 & 19 & 484 & 49 & 33 & 22 & 30 \\
\hline & 150.000 & 45 & 40 & 23 & 771 & 59 & 67 & 44 & 44 \\
\hline & 200.000 & 71 & 66 & 37 & 1s 110 & 67 & 63 & 42 & 61 \\
\hline & 250.000 & 73 & 67 & 37 & 1s 358 & 97 & 86 & 61 & 69 \\
\hline & 300.000 & 89 & 76 & 40 & 1s 635 & 101 & 94 & 64 & 83 \\
\hline & 350.000 & 132 & 92 & 47 & 1s 952 & 115 & 109 & 72 & 96 \\
\hline & 400.000 & 119 & 104 & 57 & 2s 216 & 129 & 121 & 83 & 114 \\
\hline & 450.000 & 132 & 118 & 61 & 2s 513 & 147 & 131 & 90 & 129 \\
\hline \multirow{11}{*}{$\begin{array}{l}\frac{\pi}{0} \\
\frac{0}{0} \\
\frac{\pi}{0} \\
: \overline{0} \\
\stackrel{0}{0} \\
\dot{0}\end{array}$} & 500.000 & 150 & 129 & 65 & 2s 771 & 164 & 151 & 101 & 134 \\
\hline & 50.000 & 849 & 714 & 1s 143 & 1s 601 & 770 & 724 & 1s 671 & 1s 192 \\
\hline & 100.000 & 3s 52 & 1s 429 & 2s 292 & 3s 337 & 1s 544 & 1s 450 & 3s 335 & 2s 411 \\
\hline & 150.000 & 3s 898 & 2s 185 & 3s 595 & 8s 907 & 2s 260 & 2s 217 & 5s 257 & 3s 591 \\
\hline & 200.000 & 4s 129 & 2s 875 & $4 s 742$ & 6s 832 & 2s 951 & 2s 897 & 6s 908 & 4s 746 \\
\hline & 250.000 & 18s 593 & 3 s 670 & 6s 103 & 24s 512 & 3s 769 & 3s 701 & 8s 746 & $6 s 30$ \\
\hline & 300.000 & $1 d$ 22s 393 & $30 s 470$ & $30 s 417$ & $1 d$ 23s 84 & $16 s 260$ & $15 s 705$ & 16s 832 & $16 \mathrm{~s} 601$ \\
\hline & 350.000 & $1 \mathrm{~d} 24 \mathrm{~s} 931$ & $37 s 946$ & $37 s 612$ & $1 \mathrm{~d} 40 \mathrm{~s} 669$ & 26s 921 & $26 s 37$ & 29s 904 & $24 s 620$ \\
\hline & 400.000 & $1 d$ 36s 588 & 40s 156 & $40 s 182$ & $1 \mathrm{~d} 46 \mathrm{~s} 732$ & 41s 890 & 41s 706 & 41s 427 & $41 \mathrm{~s} 470$ \\
\hline & 450.000 & $1 d$ 55s 205 & 47s 495 & $47 s 168$ & $1 \mathrm{~d} 56 \mathrm{~s} 104$ & 46s 497 & 46s 945 & 47 s 628 & 47s 308 \\
\hline & 500.000 & $2 \mathrm{~d} 8 \mathrm{~s} 421$ & 58s 356 & $1 \mathrm{~d} 8 \mathrm{~s} 27$ & $2 \mathrm{~d} 10 \mathrm{~s} 353$ & 51s 368 & 51s 625 & 51s 335 & 51s 620 \\
\hline
\end{tabular}

Tablo 5'de verilen 4. sorgu, tablonun içindeki tüm kayıtlar için doğum tarihlerini sıraladığından ve tüm hastaların tanımlayıcısını doğum tarihlerine göre siralı olarak döndürdüğünden, en karmaşı sorgudur. Bu yüzden, hem şifresiz, hem şeffaf şifreli, hem de şifreli veri üzerindeki çalıșma süresi uzundur. Tablo 5'deki süreler incelendiğinde
150.000 kayıttan sonra, sürelerde hızlı bir artış olduğu görülmektedir. Bunun nedeni, veri büyüklüğünün artması ile hafızanın dolması, ardından işlemlerin disk üzerinde yapılmasıdır.

\section{Sonuçlar ve Gelecek Çalışmalar}

Elektronik sağlık kayıtları içeren veri tabanlarındaki içeriğin gizliliğinin ve 
mahremiyetinin sağlanması için şifreleme tabanlı sistemlere ihtiyaç duyulmaktadır. Şifreleme süreçlerinin gerçekleştirilmesinde sistemin performansı önemli bir kriter olarak karşımıza çıkmaktadır. Bu çalışmada öncelikle vekil tabanlı bir sistem olan CryptDB ile T-SQL karşılaştırılmıştır. Kolay entegre olması ve sistemin performansını iyileștirmesi nedeniyle CryptDB gibi vekil tabanl sistemlerin kullanımı öne çıkmakla beraber, bu sistemlerin henüz stabil çalıştığını söylemek mümkün değildir. $\mathrm{Bu}$ nedenden dolayı, bu çalışmada T-SQL ile veri tabanının şifrelenmesi uygulamaları üzerine yoğunlașılmıș ve yapılan deneylerin sonuçları tablolar halinde verilmiştir. T-SQL kullanıldığında ve sütun bazlı şifreleme yapıldığında veri tabanında tutulan verilerin büyüklügünün ortalama 11 kat arttığı ve sorgulama sürelerinin saniyelerden dakikalara yükseldiği gözlenmiştir. Şeffaf şifreleme yapıldığında sorgulama süresi ortalama yüzde 23,78 artmaktadır, şifreleme yapıldığındaysa da ortalama yüzde 25961,28 artmaktadır.

Günümüzün depolama imkânları düşünüldüğünde, verilerin büyüklüğünün artması ciddi bir problem değildir. Daha güçlü işlemci ve mimariye sahip sunucuların kullanılması ile de sorgulama süreçlerinin hızlanması mümkündür. Şeffaf veri şifreleme (TDE) kullanıldığında sorgulamalar çok daha hızlı gerçekleşmektedir. Ancak bu yöntemin dezavantajları, Microsoft SQL Server'ın Enterprise sürümünü gerektirmesi ve süreç içerisinde ara bellekte verilerin şifrelenmemiş olarak durmasidir.

Veri tabanındaki bütün alanlar yerine bir kısmının şifrelenmesi (kısmi şifreleme) ya da verilerin anonimleştirilmesinin şifreleme sürecinin performansını olumlu yönde etkilediği de gösterilmiştir.

Gelecek çalışmalarda; farklı bilgisayarlar üzerinde testler yapılarak performans kıyaslanması, ayrıca bulut yapısı üzerinden de T-SQL testlerinin yapilması hedeflenmektedir. Şifrelemede kullanılan anahtarların dağıtımı, veri tabanının belli tablolarına birden fazla kullanıcının bağlanmasına izin verebilecek grup anahtarlama sistemleri ileriki çalışmalarda incelenecektir.

\section{Kaynakça}

[1] Karaarslan, E., Ergin, A.M., Turğut, N., Kılıç, Ö. 2015. Elektronik Sağlık Kayıtlarının Gizlilik ve Mahremiyeti. XX. Türkiye'de İnternet Konferansı, 1-3 Aralık, İstanbul, 217-222.

[2] Tsai, K.L., Leu, F.Y., Wu, T.H., Chiou, S.S., Liu, Y.W., Liu, H.Y. 2014. A Secure ECC-based Electronic Medical Record System, Journal of Internet Services and Information Security, Cilt. 4, No. 1, s. 47-57.

[3] Fernández-Alemán, J.L., Señor, I.C., Lozoya, P.Á.0., Toval, A. 2013. Security and Privacy in Electronic Health Records: A Systematic Literature Review, Journal of Biomedical Informatics, Cilt. 46, No.3, s. 541-562. DOI:10.1016/ j.jbi.2012.12.003

[4] Mohammed, N., Barouti, S., Alhadidi, D., Chen, R. 2015. Secure and Private Management of Healthcare Databases for Data Mining. IEEE 28th International Symposium on Computer-Based Medical Systems, 22-25 Haziran, São Carlos ve Ribeirão Preto, 191196. DOI: $10.1109 / \mathrm{cbms} .2015 .54$

[5] Popa, R.A., Redfield, C.M.S., Zeldovich, N., Balakrishnan, H. 2011. CryptDB: Protecting Confidentiality with Encrypted Query Processing, 23rd ACM 
Symposium on Operating Systems Principles, 23-26 Ekim, Cascais, 85100. DOI: $10.1145 / 2043556$. 2043566

[6] Schneier, B., Kelsey, J., Whiting, D., Wagner, D., Hall, C., Ferguson, N. 1998. Twofish: A 128-bit block cipher, NIST AES Proposal. https://www.schneier.com/acade mic/paperfiles/paper-twofishpaper.pdf (Erişim Tarihi: 27.10.2017).

[7] Daemen, J., Rijmen, V. 1998. AES Proposal: Rijndael, NIST AES Proposal. http://csrc.nist.gov/ archive/aes/rijndael/Rijndaelammended.pdf (Erişim Tarihi: 27.10.2017).

[8] Rankins, R., Bertucci, P., Gallelli, C., Silverstein, A.T. 2015. Microsoft SQL Server 2014 Unleashed, Pearson Education, ABD, 1992s.

[9] Naveed, M., Kamara, S., Wright, C.V. 2015. Inference Attacks on Property-Preserving Encrypted Databases, 22nd ACM SIGSAC Conference on Computer and Communications Security, 12-16 Ekim, Denver, 644-655. DOI: 10.1145/2810103.2813651

[10] Patel, D., Jiang, Y. 2013. Overview of CrytpDB, CPSC 5670 Dönem Ödevi. http://www.utc.edu/centerinformation-security-assurance/ pdfs/course-paper-5670-cryptdb. pdf (Erişim Tarihi: 27.10.2017).

[11] SQL-Like queries in CRYPTDB doesn't work, 2015. http://crypto.stackexchange.com/ questions/26423/sql-like-queriesin-cryptdb-doesnt-work (Erişim Tarihi: 08.03.2016).
[12] Skiba, M. 2015. Analysis of Encrypted Databases with CryptDB, Bitirme Tezi, Bochum: Ruhr-University Bochum, Chair for Network and Data Security, s. 40, http://www.nds.rub.de/media/ei/ arbeiten/2015/10/26/thesis.pdf (Erişim Tarihi: 27.10.2017).

[13] Dayıoğlu, Z. 2014. Secure Database in Cloud Computing-Cryptdb Revisited, International Journal of Information Security Science, Cilt. 3, No. 1, s. 129-147.

[14] Akın, İ.H., Sunar, B. 2014. On the Difficulty of Securing Web Applications using CryptDB, IEEE Fourth International Conference on Big Data and Cloud Computing, 3-5 Aralık, Sidney, 745-752. DOI: 10.1109/bdcloud.2014.75

[15] Coles, M. 2007. Pro T-SQL 2005 Programmer's Guide, Apress, New York, 560s.

[16] Microsoft CAPI, 2016. http://msdn.microsoft.com/enus/library/aa380256(VS.85).aspx (Erişim Tarihi: 08.03.2016).

[17] Surveillance, Epidemiology, and End Results (SEER) Program Research Data (1973-2012), National Cancer Institute, DCCPS, Surveillance Research Program, Surveillance Systems Branch, released April 2015, based on the November 2014 submission. https://www.seer.cancer.gov (Erişim Tarihi: 08.03.2016).

[18] Natarajan, J., Bruchez, R., Coles, M., Shaw, S., Cebollero, M. 2015. Pro TSQL Programmer's Guide 4th Edition, Apress, New York, 744s. 